\title{
FORMAÇÃO DOCENTE E PRÁTICA REFLEXIVA: interesses políticos e ideológicos na interpretação do conceito
}

\begin{abstract}
PETRILLI, Silvia Regina Pincerato; ${ }^{1}$ CAMARGO, Dulce Maria Pompêo (orientadora) ${ }^{2}$

\section{Resumo}

O presente trabalho é parte da pesquisa de mestrado desenvolvida no Laboratório de Ensino, Sociedade e Cultura (LESC) do Programa de Pós-graduação em Educação da Pontifícia Universidade Católica de Campinas - PUC/Campinas, cujo objetivo foi fazer um estudo crítico sobre a formação docente, partindo da ampla disseminação e apropriação dos conceitos de professor e prática reflexiva. Buscamos pelo ser professor no exercício da profissão no interior de um grupo de formação continuada em serviço, procurando compreender o papel da formação continuada, o que aprendem no dia-a-dia do processo formador, e a importância da Universidade nesse processo. $\mathrm{O}$ referencial teórico fundamentou-se em estudos e pesquisas sobre a prática reflexiva na formação docente no Brasil e no mundo, de forma a interpretar dialeticamente a realidade educacional, possibilitando, assim, diante das inúmeras críticas ao paradigma da racionalidade técnica, compreender o papel da reflexão no desenvolvimento profissional do professor, bem como as possibilidades de mudança.
\end{abstract}

\section{Introdução}

O presente trabalho é parte da pesquisa de mestrado desenvolvida no Laboratório de Ensino, Sociedade e Cultura (LESC) do Programa de Pós-graduação em Educação da Pontifícia Universidade Católica de Campinas - PUC/Campinas, cujo objetivo foi fazer um estudo crítico sobre a formação docente, partindo da ampla disseminação e apropriação dos conceitos de professor e prática reflexiva. Trata-se de inquietações acerca dos novos moldes apontados para a formação inicial e continuada impostas no contexto das reformas implementadas a partir da década de 1990 no Brasil ${ }^{3}$ e dos estudos e pesquisas educacionais que emergiram neste contexto tecendo críticas contrárias ao paradigma da racionalidade técnica ${ }^{4}$.

Buscamos pelo ser professor no exercício da profissão no interior de um grupo de formação continuada em serviço, procurando compreender o papel da formação continuada, o que aprendem no dia-a-dia do processo formador, e a importância da Universidade nesse processo.

\footnotetext{
${ }^{1}$ Grupo de Pesquisa Laboratório de Ensino, Sociedade e Cultura - LESC, Pontifícia Universidade Católica de Campinas - PUC/Campinas - Brasil - e-mail: sppetrilli@ig.com.br

${ }^{2}$ Grupo de Pesquisa Laboratório de Ensino, Sociedade e Cultura - LESC, Pontifícia Universidade Católica de Campinas PUC/Campinas - Programa de Pós Graduação em Educação - Campinas/SP - Brasil - e-mail: dpompeo@mpc.com.br

${ }^{3}$ Reforma que objetivava adequar políticas educacionais aos ajustes econômicos e políticos mundiais, regidos pelo ideário neoliberal, num contexto de reorganização capitalista em nível mundial. Palavras chave: implementação de novas tecnologias; mercado de trabalho e novas competências. Dessa forma, a reforma educacional se articula com a reordenação capitalista, que é enriquecida de conteúdo ideológico, justificando os problemas sociais e econômicos.

${ }^{4}$ Modelo de ensino que separa teoria e prática e supervaloriza área do conhecimento específico que se vai ensinar, onde na prática pedagógica - apesar da sua complexidade - são encaminhadas soluções simplistas, descontextualizadas.
} 
O referencial teórico fundamentou-se em estudos e pesquisas sobre a prática reflexiva na formação docente no Brasil e no mundo, de forma a interpretar dialeticamente a realidade educacional, possibilitando, assim, diante das inúmeras críticas ao paradigma da racionalidade técnica, compreender o papel da reflexão no desenvolvimento profissional do professor, bem como as possibilidades de mudança.

\section{Desenvolvimento}

Nos últimos anos, diante dos inúmeros debates e pesquisas, percebemos claramente o clima de tensão que afetou e afeta os professores e sua formação ao serem chamados ou responsabilizados pelas urgentes transformações na educação. Os temas mais comuns trazidos para o debate são: competências; identidade; reflexão; racionalismo técnico; saberes práticos e teóricos; sistema educacional; reformas, enfim, estudos que falam da pessoa e da formação inicial e continuada de docentes nos contextos educacionais da atualidade.

Sem medo de errar, a reflexão é o elemento central nesses estudos, debates e pesquisas que tentam, a todo momento, mostrar a importância do fazer docente relacionado à ação de buscar novos caminhos para antigas questões difíceis do fazer docente, e uma possibilidade de aproximar teoria e prática dentro de uma proposta de formação para a reflexão. Afirmam, ainda, que o professor precisa conhecer essa nova realidade, entendê-la para poder nela atuar, traduzindo este esforço de reconhecer-se e transformar-se num processo de formação contínuo ao longo da sua carreira profissional.

A sociedade, nesse contexto neoliberal, traz a idéia de competição e competitividade a todas as relações sociais. Relacionam o homem, os fatos, os sentimentos e pensamentos a novos métodos de formação e de informação em processos contínuos e permanentes, onde tudo tem um preço, inclusive a educação que, a cada dia, se vê mais desacreditada.

A década de 90, chamada década da educação, demarca questões importantes sobre a formação docente, em que as preocupações com a pesquisa e com a prática dos professores tornam-se mais explícitas. A formação continuada articulada às experiências de vida dos professores torna-se objeto de interesses nas pesquisas. Há toda uma nova recomposição do cenário educacional, representando o aprofundamento das políticas neoliberais. A educação e a formação de professores ganham, nesse contexto, importância para a realização das reformas educativas.

Com a Lei de Diretrizes e Bases da Educação Nacional (Lei no. 9.394/96), efetiva-se a descentralização financeira, passando para encargo dos municípios o Ensino Fundamental e, dos Estados o Ensino Médio. Nesse contexto de transição, muitas são as ações promovidas pelas reformas:

Educação para Todos, Plano Decenal, Parâmetros Curriculares Nacionais, diretrizes curriculares nacionais para a educação básica, para a educação superior, para a educação infantil, educação de jovens e adultos, educação profissional e tecnológica, avaliação do SAEB - Sistema Nacional de Avaliação da Educação Básica - Exame Nacional de Cursos (Provão), ENEM - Exame Nacional do Ensino Médio - descentralização, FUNDEF - Fundo de Manutenção e desenvolvimento do Ensino Fundamental e de Valorização do Magistério - Lei da Autonomia Universitária, novos parâmetros para as IES, são medidas que objetivam adequar o Brasil à nova ordem, bases para a 
reforma educativa que tem na avaliação a chave-mestra que abre caminho para todas as políticas: de formação, de financiamento, de descentralização e gestão de recursos (FREITAS, 2002).

Em meio a tantas mudanças, com as quais se articula toda a sociedade capitalista, a qualidade da educação é tida como a meta do governo para a educação no Brasil, de forma a considerar que a formação profissional é o único caminho que leva à obtenção da qualificação desejada. Como consequiência, vemos uma enorme expansão dos Institutos Superiores de Educação com a finalidade específica de formar professores para a educação básica e especialistas de educação. Juntamente a essa expansão, observamos uma acelerada busca por títulos por parte dos docentes a fim de se adequarem às novas exigências legais apontadas na Legislação quanto à formação docente:

A formação inicial em nível superior é fundamental, uma vez que possibilita que a profissionalização se inicie após uma formação em nível médio, considerada básica e direito de todos. Entretanto, não se pode desconsiderar que uma formação em nível superior não é, por si só, garantia de qualidade. É consenso que nenhuma formação inicial, mesmo em nível superior, é suficiente para o desenvolvimento profissional, o que torna indispensável a criação de sistemas de formação continuada e permanente para todos os professores (BRASIL, 1999, p. 17).

Para efeito de análise, retomamos o trecho acima como forma de elucidar a dimensão dessas transformações e sua repercussão para a formação docente no âmbito municipal, uma vez que, a partir de agora, os municípios são responsáveis pela elaboração do plano de carreira e, com este, a valorização ou delineamento da formação docente inicial e continuada.

Com isso, há uma grande oferta de cursos de curta duração e ou a oferta de formação inicial com procedência duvidosa e, ainda, de forma acelerada aos professores que financiam a sua própria formação, a educação vira objeto de consumo, alimentando os interesses das políticas educacionais neoliberais, tornando-se um fácil elemento e um grande facilitador do processo de acúmulo de capital. Essa busca pela qualificação, ou melhor dizendo, pela titulação tornou-se um discutível mecanismo de formação docente e, como escrevemos anteriormente, um importante e lucrativo meio para as instituições privadas.

Será que estamos vivendo um processo de aceleradas transformações que resultam na formação ou na deformação dos profissionais do magistério? Os discursos reformadores, que elevam o patamar das exigências requeridas dos professores, em diferentes frentes, trabalham, de fato, no sentido de valorizar a profissão docente tão desgastada e desacreditada diante da sociedade de forma geral?

Assim, em meio a tantas diretrizes, a formação continuada em serviço surge como uma possibilidade de formação permanente, como processo prolongado pela vida toda, em contínuo desenvolvimento, como um dos importantes espaços formativos, materializado pela atual política educacional e que, de certa forma, traduz em um direito e em uma possibilidade de agregar uma valorização ao salário e à carreira docente.

Continuidade da formação profissional, proporcionando novas reflexões sobre a ação profissional e novos meios para desenvolver e aprimorar o trabalho pedagógico; um processo de construção permanente do conhecimento e desenvolvimento profissional, a partir da formação inicial e vista como uma proposta mais ampla, de hominização, na qual o homem integral, omnilateral, produzindo-se a si mesmo, também se produz em interação com o coletivo (ANFOPE, 1998). 
Esse espaço coletivo tem sido motivo de inúmeras discussões que permeiam o debate nacional e internacional diante da crise educacional brasileira que, na verdade, é apenas uma das várias vertentes de uma problemática (política, social e econômica) mais ampla.

Em meio a esse cenário de transformações, é divulgada a falsa ilusão de que as tão almejadas transformações, que rompem com antigas concepções de que o professor é um mero técnico e de que ensinar é algo simples, só dependem da boa vontade e de treinamento. A intensificação dos debates em favor da qualidade da educação escolar, nos meios de comunicação e de informação, tem o objetivo de acelerar o processo de transformação diante da opinião pública, tornando-o, aos olhos do governo, um fato.

À medida que são implementadas as políticas educacionais, baseadas em estudos para além das críticas ao tecnicismo, começamos a reconhecer a complexidade da prática pedagógica, sinalizando para a importância de uma formação pautada na prática concreta e material desenvolvida em sala de aula. Buscam-se novos enfoques e paradigmas a fim de se compreender a prática docente, os saberes pedagógicos e epistemológicos relativos aos conteúdos ensinados e aprendidos nas escolas e até então pouco valorizados.

Segundo GERALDI (1998), os estudos que valorizam a importância da escrita reflexiva sobre a realidade escolar com o objetivo de compreendê-la; a necessidade de associar ensino e pesquisa na formação inicial; o respeito aos saberes docentes produzidos no local de trabalho e a necessidade de construir caminhos coletivos na escola, trazidos pelos autores da coletânea organizada por NÓVOA (1995), são preocupações importantes que devem ser consideradas no processo de formação docente, e também legitima, de alguma forma, os estudos desenvolvidos no Grupo de Estudos e Pesquisas sobre Educação Continuada (GEPEC) ${ }^{5}$.

Nesse contexto, os temas: prática reflexiva, ensino reflexivo surgem como a chave que vai dar conta de corrigir as deformações criticadas na racionalidade técnica e, com isso, a formação docente ganha os debates em vários estudos e pesquisas em vários países.

Assim, ao pesquisarmos as origens dos conceitos de formação docente e prática reflexiva, observamos que os estudos de SCHÖN (1992) tiveram maior peso na difusão e na apropriação do conceito reflexão-na-ação, definindo-o como o processo mediante o qual os professores aprendem a partir da análise e interpretação da sua própria atividade, conduzindo-os à criação de um conhecimento específico, no qual denomina de tácito e pessoal, ligado à ação, que se manifesta espontaneamente no desempenho das suas ações. Destaca que o modelo da racionalidade técnica não dá conta das zonas indeterminadas da prática que são caracterizadas pela complexidade, incerteza, instabilidade, singularidade e conflito de valores. Destaca, ainda, que o saber-fazer, teórico e prático, que deve ter o profissional é que permite agir em realidades complexas e particulares que são caracterizadas por essas zonas de indefinição e que exigem a reflexão-na-ação - um diálogo reflexivo - com a realidade apresentada. Valoriza a experiência e a reflexão sobre essa experiência, pois o conhecimento é construído na ação e não antes dela como propõe o modelo da racionalidade técnica ao apresentar primeiro a ciência, depois a sua

\footnotetext{
${ }^{5}$ GEPEC: Grupo de Estudos e Pesquisas sobre a Educação Continuada coordenado por Corinta Maria Grisolia Geraldi e Guilherme do Val Toledo do Prado, na UNICAMP.
} 
aplicação e, por último, o estágio, pressupondo que os alunos irão aplicar o conhecimento adquirido no seu processo de formação.

Ao valorizar os conhecimentos práticos dos professores, como ponto de partida e de chegada, inúmeros estudos e pesquisas sobre a formação docente, abrem perspectivas para a valorização da pesquisa na prática docente, uma prática refletida, investigativa, que possibilita responder às situações novas, dando sustentação para o aparecimento de mais um conceito: o de professor pesquisador.

Se, por um lado, esses conceitos têm sido bastante discutidos e valorizados nos debates e pesquisas educacionais, por outro, têm gerado apropriações mal compreendidas que, na prática, revelam suas contradições.

No Brasil, dois importantes grupos de estudos e pesquisa em duas Universidades ${ }^{6}$ acolhem o conceito de professor reflexivo com o objetivo de compreendê-los com base na investigação, no aprofundamento e na análise crítica, apontando limites e possibilidades para a fecundidade de uma perspectiva teórica para a formação de professores.

O eixo articulador desses grupos centra-se na necessidade de se ler criticamente a realidade por meio de uma análise mais sistemática, atentando para os contextos políticos, sociais, econômicos e culturais em que foram produzidos; para a complexidade da prática pedagógica; para a complexidade do processo de apropriação e produção dos saberes docentes e, consequentemente, para os processos de formação de professores.

\title{
Para PIMENTA (2002):
}

\begin{abstract}
A centralidade colocada nos professores traduziu-se na valorização do seu pensar, do seu sentir, de suas crenças e seus valores como aspectos importantes para se compreender o seu fazer, não apenas de sala de aula, pois os professores não se limitam a executar currículos, senão que também os elaboram, os defendem, os re-interpretam. Daí a prioridade de se realizar pesquisas para se compreender o exercício da docência, os processos de construção da identidade docente, de sua profissionalidade, o desenvolvimento da profissionalização, as condições em que trabalham, de status e de liderança (p. 36).
\end{abstract}

Com a disseminação e a apropriação do conceito de professor reflexivo, amplia-se também a análise crítica a partir das idéias de SCHÖN (1992) e, com isso, começa-se a pensar todas as dimensões organizativas da escola: currículo necessário à formação de professores reflexivos e pesquisadores; local de formação; condições de exercício de uma prática profissional reflexiva; processos de formação; projeto pedagógico; trabalho coletivo; autonomia; identidade profissional e pessoal; histórias de vida; novas tecnologias na sociedade da comunicação e da informação etc., trazidos e divulgados por meio dos textos de autores da Espanha, Portugal, França, Estados Unidos e Inglaterra e ainda com as freqüentes vindas de educadores portugueses convidados pelas Universidades brasileiras, associações científicas, governos e escolas particulares.

\footnotetext{
${ }^{6}$ UNICAMP - GEPEC coordenado por Corinta Maria Grisolia Geraldi e Guilherme do Val Toledo do Prado e Universidade de São Paulo (USP)coordenado por Selma Garrido Pimenta e do professor Evandro Ghedin.
} 


\section{Segundo estudos desenvolvidos por PIMENTA (2002):}

(...) no solo que acolheu as colaborações dos pesquisadores estrangeiros, pode-se apontar o seguinte: a valorização da escola e de seus profissionais nos processos de democratização da sociedade brasileira; a contribuição do saber escolar na formação da cidadania; sua apropriação como processo de maior igualdade social e inserção crítica no mundo (e daí: que saberes? que escola?); a organização da escola, os currículos, os espaços e os tempos de ensinar e aprender; o projeto político e pedagógico; a democratização interna da escola; o trabalho coletivo; as condições de trabalho e de estudos (de reflexão), de planejamento; a jornada remunerada, os salários, a importância dos professores nesse processo, as responsabilidades da universidade, dos sindicatos, dos governos nesse processo; a escola como espaço de formação contínua, os alunos: quem são? de onde vêem? o que querem da escola? (de suas representações); dos professores: quem são? como se vêem na profissão? Da profissão: profissão? E as transformações sociais, políticas, econômicas, do mundo do trabalho e da sociedade da informação: como ficam a escola e os professores? (p.35).

O conceito encontrou solo fértil em função do momento histórico, político e social em que foram facilmente disseminados: pesquisa e prática não conjugavam o mesmo verbo; não se possibilitava a reflexão dos professores e nem a dos alunos; Ensino Normal era apenas uma habilitação profissionalizante; grande influência da ditadura militar; pesquisas distantes da realidade escolar; baixos salários; grande movimentação sindical etc.

Dessa forma, podemos compreender como as temáticas inovadoras foram facilmente configuradas em nosso país, através da colaboração dos pesquisadores estrangeiros, numa tentativa de valorizar a escola, o professor e, consequentemente, a formação docente como um todo e como uma nova possibilidade.

Mas será que essa valorização não pode ser feita levando em consideração personagens reais em contextos e prática também reais? Será que estamos falando da mesma prática, aquela proposta pelos autores da reforma e aquela realizada nas salas de aula brasileira? Será que esta mesma prática resultante de um tempo e inserida num espaço cheio de diferentes representações e valores que se contradizem e que estão presentes na atual sociedade poderá transformar-se, segundo as diretrizes, para a formação docente? Analisando pelo lado do professor, será que suas vozes, seus conhecimentos e representações foram levados em consideração nesse processo de reforma, já que ouvir o que pensam, o que fazem e como fazem é de extrema importância, conforme apontam as pesquisas?

No contexto brasileiro, nos últimos vinte anos mais ou menos, as políticas educacionais centraram esforços nas questões da escola e da formação do professor, em meio a um cenário em que transformar era necessário, e viraram a varinha mágica para se resolverem os problemas da educação, considerando que o professor está mal formado.

A sensação que temos é a de que aderimos completamente a uma moda, incorrendo em um equívoco político, ideológico, histórico e teórico, se considerarmos a quantidade de estudos e pesquisas divulgados sobre a importância da reflexão na profissão docente no país. Parece até que acreditamos que a formação do professor é a escola quem faz, conforme determina o paradigma idealista, não levando em consideração a nossa realidade, nossos contextos e personagens, mas sim divulgando estudos, pesquisas e propostas para pessoas como forma concreta de transformação. Um princípio completamente idealista, se pensarmos que a formação de professores e o professor reflexivo resolvem os problemas educacionais. 
Independentemente do paradigma, entendemos que os professores, nas escolas, são reflexivos, pois a educação e, com ela, a escola e os professores são personagens reais, pensantes, envolvidos em uma prática social, histórica, concreta e diretamente associada a uma prática política, que transmite modelos, que forma e que se forma ao mesmo tempo. Escola e professores que dependem diretamente uns dos outros ou são diretamente afetados por forças políticas e sociais.

Dentro dessa linha de raciocínio, quais são as condições docentes de trabalho? Quem são esses sujeitos? Quais condições que têm dentro da escola? Como ser reflexivo com 40 horas semanais de trabalho? O que pensam sobre a importância da leitura e da escrita, sobre os seus registros, sobre suas reais condições de trabalho? Será que estamos problematizando os conceitos realmente importantes em nosso cenário educacional?

As políticas para a formação docente, ao assumirem a meta de transformar a realidade a partir da reflexão - como se os professores não fossem reflexivos - promulgam a falsa ilusão de que os professores não sabem nada, ou fazem tudo errado, desqualificando suas práticas, não valorizando sua história de vida e de profissão.

Dessa forma, entender a cultura escolar ${ }^{7}$, seus personagens, relações e conflitos se faz necessário nesse momento, pois não podemos pensar em transformar o cenário educacional e, com ele, o professor e suas práticas sem antes localizá-los historicamente, levando em consideração que estes são os principais envolvidos nesse processo.

Se voltarmos a Marx, encontraremos uma categoria fundamental chamada trabalho como princípio educativo que, neste momento, nos obriga a fazer uma análise mais detalhada dos mais variados elementos que envolvem a prática educativa.

Certamente Marx não formulou uma teoria, com princípios metodológicos e diretrizes, para a educação. Sua preocupação era o estudo das relações sócio-econômicas e políticas e seu desenvolvimento no processo histórico. Mas então, qual a sua importância para a educação?

A compreensão vem a partir da concepção de que a educação está intimamente relacionada com a perspectiva sócio-econômica. Para ele, a humanização da sociedade e pela sociedade se dá através do trabalho. Por isso, o ser humano, portanto biológico e social, está sempre em movimento, em processo de transformação, e tem o seu lugar num dado momento histórico. Para compreender essa perspectiva educação/trabalho, partimos do princípio de que o homem produz a sua existência baseada no trabalho, isto é, em um processo produtivo e reprodutivo dentro da sociedade.

A história da educação brasileira tem sido marcada fortemente pelas reformas educacionais, pelos inúmeros debates pedagógicos e apolíticos, pela idéia de uma escola universal para todos, materializada nas intenções de quem as idealizou, que, acima de tudo,

\footnotetext{
${ }^{7}$ Entendemos cultura escolar nas palavras de DOMINIQUE (2001, p.10) como o conjunto de normas que definem conhecimentos a ensinar e condutas a inculcar, e um conjunto de práticas que permitem a transmissão desses conhecimentos e a incorporação desses comportamentos, normas e práticas coordenadas a finalidades que podem variar segundo épocas.
} 
neste início de século, está desacreditada, o que percebemos é um grande esforço para recuperar o seu prestígio através dos discursos de melhoraria de sua qualidade e, com isso, fortalecer os debates sobre a formação de professores e sobre a prática pedagógica.

Essa escola, histórica e erroneamente concebida com base na idéia de que o país é grande, e de que nele podem conviver como iguais ricos, pobres, industriais, industriários, foi construída a partir de duas perspectivas: a primeira voltada para uma formação técnica, marcada pela instrumentação necessária para o exercício de uma dada profissão, e outra, mais intelectual, que trabalha com o conhecimento de excelência. Nesse contexto de duplas intenções, promove-se a falsa idéia de que há oportunidades para todos, bastando o esforço de cada um para atingi-lo. Por outro lado, também, possibilitando o acesso de uma grande parcela da população à escola, não se discutindo que tipo de ensino nela é oferecido. Como resultado dessa interpretação histórica do processo educacional, faz-se a separação do trabalho braçal e intelectual e, com isso, indiretamente:

(...) esvazia-se o trabalho intelectual de seu conteúdo duro, disciplinado, muscular e nervoso. O estudo perde o sentido de trabalho e a disciplina externa é considerada negativa. Aula e estudo não são propriamente trabalhos; estudar não é jornada de trabalho, é antes um não-trabalho. Assim, ter um emprego de dia e estudar à noite não representa propriamente uma dupla jornada de trabalho, quando, na verdade, o estudo sério para quem está empregado é um segundo trabalho ainda mais duro: com isso, no momento em que o mundo do trabalho entra na escola, o rigor científico se afasta dela (NOSELLA, 1998, p.52).

Nesse sentido, também se constrói a idéia de que estudar não demanda esforço, busca-se a titulação sem esforço, uma formação de faz-de-conta, segundo a qual um ensina e um outro paga, mas não aprende. Implementa-se, assim, o mercado de títulos, o que configura a escola como um lugar de relações mais amenas, íntimas, familiares, uma extensão da casa, desfigurando de vez a função de escola como lugar de construção de conhecimento.

Onde fica a relação ensino-aprendizagem? O conhecer, o explicar, o compartilhar, o construir, o avaliar, nesse processo? Como o aluno terá condições de concorrer aos caminhos da Universidade? Aquela tida por excelência e não aquela que oferece titulação e falso compromisso de acesso ao mercado de trabalho por meio do seu discurso de formação por competências.

Perguntamos, então, o trabalho como princípio educativo forma ou deforma os professores? Será que estes são vilões ou vítimas de um processo que, por um lado, valoriza a cultura escolar e, por outro, a obtenção de títulos e não uma formação que faz sentido na prática?

Ao desfigurar a lógica do trabalho intelectual, a primeira vítima desse processo foi o mestre, o professor. Este profissional do trabalho perdeu a referência precisa do que exatamente deve saber, de como deve ensinar e avaliar. Assim, perdeu a essência de sua identidade profissional. O populismo confundiu mestre-escola com um vago assistente social; confundiu a escola com melancólicos cursos noturnos que distribuem diplomas; confundiu alfabetização orgânica com abstrata iniciação técnica no uso do alfabeto (NOSELLA, 1998, p. 61).

NOSELLA (1998), ao buscar em GRAMSCI (1975) uma outra interpretação, salienta a importância da escola articulada com o trabalho, que centra a teoria social na idéia de liberdade concreta, universal e historicamente construída na liberdade, gestada pelo trabalho e universalizada pela luta política. Essa idéia de liberdade, resultante do amor a um processo de 
produção viva, latente, de muito trabalho, de luta diária e até de sofrimento, tem muito a ver com o ser professor, no sentido real do seu trabalho na escola com os alunos, com as famílias, com a direção, e também com o contexto social em que vive. Um trabalho que, ao mesmo tempo, se dá entre as diretrizes científicas, filosóficas e ferramentas técnicas.

(...) o trabalho é a própria oficina-escola que forja o homem na prática produtiva, projetando, se estendendo e concretizando vários outros tipos de escolas de cultura, de política para melhor adaptar esse homem ao novo tipo de prática produtiva necessária naquele momento histórico (NOSELLA, 1992, p. 127).

Portanto essa idéia de liberdade apresentada busca construir uma relação que valoriza o professor como um trabalhador que se dedica todos os dias à escola, aos seus alunos, dentro e fora dela, e que, acima de tudo, é um ser humano, com aspirações, criatividade, afetividade, intelectualidade e concepções próprias construídas ao longo da sua vida. Um professor que se faz e se re-faz todo dia, dentro de um complexo cenário político, econômico, social e que constrói a escola que aí está, a partir de uma cultura escolar marcada pelo real por meio das suas práticas, também reais, como produto de um momento concreto e histórico.

Nesse processo de libertação da escola através do trabalho, é fundamental que tenhamos a consciência de que é com esse mesmo trabalho que devemos recuperar o sentido real da escola. É preciso dar significativa valorização ao fazer docente, num processo que, ao mesmo tempo em que o distingue como particular e único, o caracteriza e o identifica como um processo mais universal. É preciso compreender o movimento histórico entre o universal e o particular que está implicitamente relacionado à técnica e à ciência, entre a história e a filosofia e assim, compreender a formação do professor, suas práticas, com base na história pensada e refletida. Cada professor, ao tratar de sua prática docente, deve pensá-la a partir da elaboração histórica de sua própria vivência e não a partir das teorias estabelecidas.

\section{Conclusão}

Nessa perspectiva histórica, este estudo não tem a intenção de criticar, mas, de defender a luta por uma escola integradora, procurando encontrar caminhos, anunciar propostas, com base em sujeitos, contextos e problemas reais. Percebemos que as estratégias que apregoam a reprodução de pensamentos com efeitos apocalípticos, como o de que, para inovar é preciso somente refletir sobre a ação, sobre a reflexão na ação, para, assim, estarmos ou entrarmos em consonância com nossas próprias teorias, desqualificam ainda mais o professor e sua prática, não levando em consideração os personagens e os contextos em que estão inseridos.

Precisamos compreender que a implementação de mudanças educacionais não acontece apenas pela aplicação de uma nova legislação ou de uma fórmula mágica pronta para ser utilizada. É preciso que haja uma consonância entre políticas públicas, especificidade e a história de cada uma das redes públicas a ser levada em consideração no momento em que são definidas e implementadas mudanças oficiais. Para que as mudanças não ocorram apenas de cima para baixo, é necessário o comprometimento ${ }^{8}$ dos professores e das comunidades com a formulação

\footnotetext{
${ }^{8}$ Comprometimento entendido como um ato de estar no mundo; saber-se nele; ter consciência do mundo em que se vive para agir; um sujeito histórico e concreto (FREIRE, 1987).
} 
das políticas públicas, discutindo, unindo esforços, para a implementação de mudanças no sistema educacional.

\section{Referências Bibliográficas}

Alarcão, I. (1996). Formação reflexiva de professores: estratégias de supervisão. Portugal: Porto Editora.

Anfope. Encontro Nacional, 9. (1998). Documento final. [em linea]. Disponível em: www.lite.fae.unicamp.br/grupos/formac/docanfope/capa.html. [consulta 2005, 23 de janeiro].

Brasil, Lei 9394. (1996). Lei de Diretrizes e Bases da Educação Nacional. Estabelece as diretrizes e bases da educação nacional. Brasília, DF: Diário Oficial da União.

Dominique, J. A (2001).Cultura escolar como objeto histórico. Revista brasileira de história da educação n. 1 jan./jun.

Freire, P. (1987). Educação e mudança. Rio de Janeiro: Paz e Terra.

Freitas, H.C.L. (2002). Formação de Professores no Brasil: 10 anos de embate entre projetos de formação. Educação \& Sociedade. 23(80), 136-167.

Geraldi, C.; Messias, M.G.M e Guerra, M. D.S. (1998). Refletindo com Zeichner: um encontro orientado por preocupações políticas, teóricas e epistemológicas. En: Geraldi, C.M.G., Fiorentini, D. e Pereira, E.M. de A. Cartografias do trabalho docente: professor (a) - pesquisador (a). (pp.237-274). Campinas-SP: Mercado de Letras: A.L.B.

Gramsci, A. (1975). Quaderni del Carcere. Torino, Itália: Einaudi.

Marx, K. (1983). Manuscritos econômicos e filosóficos. In: Fromm, E. (Org.), Conceito marxista do homem, Rio de Janeiro: Zahar.

Nosella, P. (1998). Qual o compromisso político? Ensaios sobre a Educação Brasileira pósditadura. Bragança Paulista: IFAN-CDAPH. Editora da Universidade São Francisco / EDUSF.

Nóvoa, A .(coord) (1995). Os professores e a Sua Formação. Lisboa: Dom Quixote.

Pimenta, S. G., Ghedin, E. (orgs) (2002). Professor reflexivo no Brasil: gênese e crítica de um conceito. São Paulo: Cortez.

Schön, D. (1983). The Reflective Practilioner: How Professionals Think in Action. New York: Basic Books.

Schön, D. (1992). Formar professores como profissionais reflexivos. En: Nóvoa, A. (Coord.) Os professores e sua formação. (pp. 77-91). Lisboa - Portugal: Dom Quixote. 